\title{
OS EFEITOS DA PREVIDÊNCIA RURAL PARA IDOSOS E IDOSAS DE ASSENTAMENTOS DE REFORMA AGRÁRIA DO PONTAL DO PARANAPANEMA, SÃO PAULO
}

\section{Danitielle Cineli Simonato id 1, Sonia Maria Pessoa Pereira Bergamasco (iD)2}

Resumo: Este artigo tem por objetivo apresentar a percepção e a relação dos idosos (as) assentados de reforma agrária com o benefício da aposentadoria rural. A pesquisa foi realizada em seis assentamentos rurais do Pontal do Paranapanema - região oeste do Estado de São Paulo. A pesquisa foi dividida em duas fases: a primeira que buscou o perfil dos idosos (as) rurais com indagações do gênero, escolaridade, faixa etária, estado civil, renda e trabalho, nesta fase foram entrevistados 177 idosos (as). Na segunda fase que se utilizou dos depoimentos orais, buscou-se compreender a percepção dos idosos (as) frente ao benefício da aposentadoria, desde o acesso, as mudanças de vida ou não, se houve melhoria da qualidade de vida ou não, qual era a posição dos idosos (as) dentro das família diante do benefício, bem como quais eram os significados atribuídos ao benefício, e, por fim qual era a a realidade do trabalho no lote e a aposentadoria. Concluiu-se que a aposentadoria trouxe mudanças significativas para os idosos (as), desde a melhora no padrão de consumo, a benfeitorias e melhoria nos lotes. Os significados atribuíduos ao benefício da aposentadoria foram: segurança, tranquilidade e felicidade. Para além, constatou-se também que mesmo com o benefício da aposentadoria os idosos (as) ainda trabalham no lote e que no que se refere a relação famíliaaposentadoria-idosos (as) estes atores vêm se tornando cada vez mais assistentes/provedores da família do que assistidos/protegidos pelas mesmas.

Palavras-chave: Previdência Rural; Envelhecimento; Qualidade de Vida; Autonomia; Família Rural.

\section{THE EFFECTS OF RURAL PENSION FOR THE ELDERLY AND ELDERLY OF SETTLEMENTS OF AGRARIA OF PONTAL DO PARANAPANEMA - SP}

Abstract: This article aims to present the perception and relationship of the elderly settlers of agrarian reform with the benefit of rural retirement. The research was carried out in six rural settlements of Pontal do Paranapanema western region of the State of São Paulo. The research was divided into two phases: the first that sought the profile of rural elderly with questions of gender, education, age group, marital status, income and work, in this phase 177 elderly (as) were interviewed. In the second phase that was used in oral statements, we sought to understand the perception of the elderly (as) of the benefit of retirement, since access, changes of life or not, whether there was an

\footnotetext{
${ }^{1}$ Doutora em Engenharia Agrícola, pela Faculdade de Engenharia Agrícola (Feagri), Universidade Estadual de Campinas (UNICAMP). E-mail: dani_simonato@yahoo.com.br.

${ }^{2}$ Doutora em Ciências pela Universidade Estadual Paulista Júlio de Mesquita Filho (UNESP). Professora Titular Faculdade de Engenharia Agrícola (Feagri/Unicamp). E-mail:
} soniaberga@yahoo.com. 
improvement in quality of life or not, what was the position of the elderly (as) within the family before the benefit, as well as what were the meanings attributed to the benefit, and finally what was the reality of work on the lot and retirement. It was concluded that retirement brought significant changes for the elderly, from the improvement in the consumption pattern, to improvements in the lots. The meanings attributed to the retirement benefit were security, tranquility and happiness. In addition, it was also found that even with the retirement benefit the elderly (as) still work in the lot and that with regard to the family-retirement-elderly relationship (as) these actors are becoming more and more assistants / providers of the family than assisted /protected by them.

Keywords: Rural Security; Aging; Quality of Life; Autonomy; Rural Family.

\section{Introdução e Referencial Teórico}

O que hoje denominamos Previdência Social teve seu início na Antiguidade. Os primeiros registros são do Oriente Médio, ainda no século XVIII a.C., como o Código de Hamurabi, na Babilônia, e o Código de Manu, na Índia, no século II a.C. Adentrando a era Cristã, temos a legislação de Sólon, na Grécia antiga, e em Roma, os Collegiae e as Sodalitatis, que conferiam algum tipo de proteção a trabalhadores carentes (BERWANGER, 2009).

Já na Idade Média, a sociedade era marcada pelo modo de produção feudalista, que tinha como características uma sociedade essencialmente camponesa, de economia agrária, teocêntrica, não comercial e praticamente amonetária. Assim, as relações sociais de produção e de trabalho eram estamentais, ou seja, possuíam pouca mobilidade social e nelas continha a figura da nobreza (senhor feudal), do clero e dos camponeses (PAIVA, 2014).

Nesse sentido, a noção de proteção aos mais vulneráveis era desempenhada pelo senhor feudal de "proteção militar", e pelo clero (Igreja), de "proteção espiritual". Esses aspectos compunham a proteção aos camponeses (servos), que eram o maior contingente populacional. Essa relação era marcada pela vassalagem e se baseava em troca, ou seja, os servos ofereciam ao senhor feudal sua força de trabalho e o pagamento de pequenas taxas (pecúnias) em troca de proteção e de pequenas glebas de terra (JARDIM, 2013).

Também vale destacar que a proteção social dos indivíduos ficava a cargo da "instituição' familiar, onde os mais velhos exerciam este papel, no papel de "pater família". Nesse mesmo período surgiram as "guildas", que tinham um espirito, sobretudo, de solidariedade, proteção e auxílio mútuo em territórios como França e Alemanha, bem como houve o surgimento de confrarias e de grêmios mutualistas, porém esta proteção era impulsionada pela expansão do cristianismo e não eram universalizadas, ou seja, não eram para todos (BERWANGER, 2009).

O surgimento da ideia do comércio e das grandes navegações, já pressupunha a ideia de liberdade e não condizia com o modo estamental e restrito do sistema feudal, modificando, significativamente, as relações sociais, a ideia de lucro e dinheiro e essas novas roupagens do sistema exerceram fortes 
pressões no sistema feudal dissolvendo-o, dando lugar aos tempos modernos dos séculos XIV e XV (BERWANGER, 2009).

Os Estados ditos modernos eram absolutistas e tinham como princípios a soberania, o território, o povo e a finalidade. Neste, nasce a ideia de separação entre a esfera pública e a esfera privada. Desta maneira, no que se refere à proteção social, surgiram as irmandades e os montepios, onde a proteção social não era conferida a todos e se restringia apenas a algumas categorias profissionais. Nesse período, surge na Inglaterra a primeira lei que deu apoio e proteção aos pobres, promulgada pelo então rei Henrique VIII, a Poor Relief Act, em 1601, que deu à comunidade a responsabilidade pela assistência aos pobres e pelo pagamento de taxas obrigatórias para manutenção dessa população; esse pagamento era centralizado nas paróquias e nas igrejas (BERWANGER, 2009).

Outro marco importante se deu no Estado neoliberal, onde em 1793 foi promulgada a Declaração dos Direitos dos Homens e do Cidadão, que dispunha em seu artigo 21: "A assistência pública é uma dívida sagrada, a sociedade deve sustentar os cidadãos infelizes, dando-Ihes trabalho ou assegurando os meios de subsistência aos que não estejam em condições de trabalhar". Embora essa tenha sido uma iniciativa de proteção aos menos favorecidos, de fato a Declaração não surtiu muito efeito.

O início da proteção social de fato garantida pelo Estado nasceu na Alemanha em 1883, do projeto do chanceler Otto Von Bismarck, criando a Lei do Seguro Social, seguro-doença, seguro contra acidentes, seguro contra invalidez e velhice. Esse projeto deu início ao que se conhece hoje como Welfare State, ou seja, o Estado de Bem-Estar Social (DEZZOTI; MARTA, 2011).

Nesse sentido, pouco a pouco vários países foram adotando a noção do "Welfare State" em tradução, "Estado de Bem-estar Social" em suas constituições, e em sua organicidade englobando tanto os aspectos da seguridade social quanto da assistência social para todas as categorias de trabalhadores (JARDIM, 2013).

Em se tratando da Previdência Rural no Brasil, tal como concebemos hoje, advém da Lei Elói Chaves de 1923. Esta nasceu do deputado paulista que teve por objetivo proteger os ferroviários, logo depois esses benefícios se estenderam para outras categorias de trabalhadores. O mecanismo de proteção tinha o modelo de Caixa, onde cada empresa guardava uma parte dos vencimentos para seus empregados em tempos de inatividade (BRUMER, 2002).

Durante a década de 1930, na era Vargas, foram promulgados outros direitos trabalhistas, como a Consolidação das Leis do Trabalho (CLT), o Fundo de Garantia por Tempo de Serviço (FGTS) e vale destacar as Caixas, que agora seriam por categorias trabalhistas e se tornariam institutos. Esses mecanismos de proteção eram voltados a trabalhadores assalariados urbanos e alguns autônomos, deixando de lado os trabalhadores rurais (BRUMER, 2002).

Decorridos os anos, em 1960 foi criada a Lei Orgânica da Previdência Social (Lops), que teve por objetivo proteger e uniformizar a proteção social aos trabalhadores rurais. Esta conquista estava ligada à reivindicação de movimentos camponeses (JARDIM, 2013).

Na década de 1960, foram tomadas as primeiras iniciativas para estender a cobertura previdenciária aos trabalhadores rurais. A primeira dessas 
iniciativas, o Estatuto do Trabalhador Rural, de 2 de março de 1963, regulamentou os sindicatos rurais, instituiu a obrigatoriedade do pagamento do salário-mínimo aos trabalhadores e criou o Fundo de Assistência e Previdência do Trabalhador Rural - FAPTR, posteriormente, em 1969, denominado Funrural. $\mathrm{Na}$ prática, a cobertura previdenciária aos trabalhadores rurais não se concretizou, pois os recursos (financeiros e administrativos) necessários à sua efetivação não foram previstos na legislação (BRUMER, 2002, p.91).

Sobre a promulgação da Constituição Federal de 1988, Jardim (2013, $\mathrm{s} / \mathrm{p})$, declara:

Em 1988, sob inspiração do Wellfare State, foi publicada no Brasil uma nova Constituição Federal, a "Constituição Cidadã". O novo texto constitucional trouxe um capítulo abordando a Seguridade Social (artigos 194 a 204), que foi dividida em Previdência Social, Assistência Social e Saúde. Num primeiro momento, o custeio da Seguridade Social seria realizado por contribuições sociais do empregador, dos trabalhadores e sobre as receitas dos concursos de prognósticos.

O sistema previdenciário brasileiro foi universalizado com a Constituição Cidadã de 1988. Naquele ano, trabalhadores e trabalhadoras rurais tiveram seus direitos reconhecidos constitucionalmente e universalmente pelo Estado brasileiro. Esse reconhecimento veio através de muita luta e reivindicação de movimentos sociais do campo, movimentos camponeses, dentre outras instituições.

Assim sendo, a Constituição de 1988 estabeleceu idade mínima para a aposentadoria, sendo 60 para homens e 55 anos para mulheres. Sobre o Sistema de Previdência Social, Delgado diz:

Ao longo das duas décadas de vigência do sistema da Previdência Rural, verifica-se que esse sistema de direito social, combinado com a política de valorização do salário-mínimo, tem efetivo impacto distributivo para as famílias rurais. Essa política irá alterar o padrão de distribuição da renda familiar, independentemente das condições produtivas dos estabelecimentos rurais familiares (DELGADO, 2015 p. 9).

Embora a Constituição Federal tenha sido um avanço na questão da Previdência Social Rural, a efetivação da mesma aconteceu apenas três anos depois com as Leis 8.212 de custeio e 8.213 de benefícios em julho de 1991, isso ocorreu diante de muitas mobilizações de trabalhadores rurais. Efetivamente, estas leis começaram a valer apenas em 1992, dando acesso universal aos idosos de ambos os sexos, as pessoas com deficiência, bem como aos agricultores familiares, desde que comprovassem a situação de produtores, parceiros, meeiros, arrendatários, garimpeiros e pescadores artesanais, bem como que exercessem tais atividades individualmente ou em regime de economia familiar, bem como seus respectivos cônjuges ou companheiros e filhos maiores de dezesseis anos (incluído pela Lei no $11.718 / 2008$ ) ou aos trabalhadores que, comprovadamente, estivessem no grupo familiar respectivo. Além disso, estas leis regulamentaram critérios como um mínimo de 180 contribuições, que correspondem a 15 anos, ou uma outra disposição importante 
é a possibilidade de aposentadoria por meio do reconhecimento da produção familiar - a alíquota incide sobre a comercialização da produção $(2,1 \%)$, o que beneficia o agricultor e a sua família, que têm acesso, por esse modo, aos benefícios previdenciários (BRUMER, 2002, BARROS, 2014, VIEIRA FILHO e MARANHÃO, 2018).

Com todos estes avanços em 2016 surgiu a Proposta de Emenda à Constituição (PEC) no 287, nesta proposta tentou-se eliminar as diferenças entre trabalhadores rurais e urbanos, bem como aumentar o tempo de contribuição, porém estas mudanças não foram aprovadas, mas as tensões e os riscos desta tentativa de mudanças foram um ataque aos agricultores familiares que exercem suas atividades laborais em condições bem diferentes do meio urbano, ainda mais em se tratando de uma população em franco processo de envelhecimento.

Diante do exposto, o objetivo do presente trabalho foi apresentar a percepção dos idosos e idosas rurais de assentamentos de reforma agrária sobre o impacto ou não do benefício da aposentadoria rural em suas vidas. Também, a problemática deste estudo se alicerça no fato dos assentados de reforma agrária se configurarem como uma categoria social com especificidades diante do universo da Agricultura Familiar brasileira.

\section{Metodologia}

\section{1 Área de Estudo - Pontal do Paranapanema - SP}

A área do território do Pontal do Paranapanema é resultante de um dos maiores grilos de terra do Brasil. Localizado na região oeste do Estado de São Paulo, faz limite com os Estados do Mato Grosso do Sul a oeste e Paraná ao sul. Especificamente, o Território do Pontal do Paranapanema é composto por 32 municípios. Essa região começou a ser ocupada desde a segunda metade do século XIX, através da grilagem de terras, por conta disso a região sempre foi marcada por muitos conflitos fundiários.

Na década de 1980/1990 houve intervenções oficiais, sobretudo, através de reassentamentos e assentamentos de populações atingidas pelas barragens hidrelétricas na região, além dos históricos conflitos fundiários. Desde então, a mobilização e luta do Movimento dos Trabalhadores Rurais Sem Terra - MST, posteriormente com o aparato do Estado no papel do ITESP e INCRA deu início a implantação de Assentamentos Rurais, a fim da regulamentação e ocupação de terras devolutas para fins de Reforma Agrária (FERNANDES, 1996).

Os assentamentos, experiências inovadoras na gestão econômica e social do território, sem dúvida, expressam tensões que são reveladoras das contradições e possibilidades da chamada agricultura familiar frente ao poder do grande capital agropecuário e agroindustrial, no âmbito do desenvolvimento social no campo paulista (FERRANTE, 2007)

Hoje, já são mais de 117 projetos de Assentamentos Rurais, com mais de 6,2 mil famílias assentadas, segundo informações do Banco de Dados da Luta pela Terra (DATALUTA, 2013).

A implantação desses projetos modificou significativamente a dinâmica da região, no que se diz respeito a economia regional, a questão fundiária, os avanços sociais e ambientais, já que, priorizou a Agricultura Familiar, ao passo 
que nesta mesma região tenha se expandido significativamente as usinas canavieiras que estão produzindo álcool, açúcar e bioenergia. Por fim esta nova roupagem do agronegócio (produção e meio ambiente) vem novamente trazendo estopim para futuros conflitos na região do Pontal (BARRETO e THOMAZ JÚNIOR (2012).

Para escolha dos Assentamentos, premeditou-se que este deveria aglutinar os mais diversos contextos possíveis. Assim, primeiro, foram selecionados assentamentos de acordo com o domínio da terra, ou seja, assentamentos do (ITESP) Instituto de Terras do Estado de São Paulo "José Gomes da Silva" e do (INCRA) Instituto de Colonização e Reforma Agrária INCRA. Dentre os inúmeros assentamentos sob o domínio destas duas instituições foram escolhidos dois (2) assentamentos de implantação mais recentes (com pelo menos cinco anos de implantação) (Assentamento Dona Carmem e Assentamento Zilda Arns) e dois (2) mais antigos (Assentamento Gleba XV de Novembro e Assentamento Água Sumida), e também, dois maiores em número de famílias/lote (Assentamento Gleba XV de Novembro e Assentamento Dona Carmem) e dois (2) menores em número de famílias/lote (Assentamento Zilda Arns e Santa Eudóxia).

Na seleção destes assentamentos vale ressaltar duas situações: primeiro, o Assentamento mais antigo do ITESP (Gleba XV de Novembro), também é o assentamento de maior número de famílias/lotes. O mesmo ocorreu quando escolhemos o Assentamento mais novo do INCRA (Dona Carmem), que também é o assentamento de maior número de famílias/lotes. Diante dessa situação, ao final foram definidos seis assentamentos rurais como áreas de estudo.

Com relação a escolha dos idosos e idosas a serem pesquisados não sabíamos ao certo a quantidade de idosos e idosas que continham nos Assentamentos, optamos pela metodologia de amostragem de Tompkin (1967) que salienta: "quando o universo amostral for menor do que 5000 indivíduos ou unidades recomenda-se uma amostragem de 50 indivíduos acrescidos de mais $2 \%$ do total da população".

Sendo assim, levamos em consideração o número de lotes como amostra total, assim calculamos para os três assentamentos maiores (Gleba XV de Novembro, Água Sumida e Dona Carmem) o número de idosos (as) para serem pesquisados, como ilustrado no Quadro 1.

\section{Quadro 1- Distribuição dos assentamentos selecionados para a pesquisa - Pontal do Paranapanema (SP).}

\begin{tabular}{|c|c|c|c|c|c|}
\hline Categorias & $\begin{array}{c}\text { Assenta- } \\
\text { mento }\end{array}$ & $\begin{array}{c}\text { Ano de } \\
\text { Criação }\end{array}$ & $\begin{array}{c}\text { Domínio } \\
\text { da terra }\end{array}$ & $\begin{array}{c}\text { Número de } \\
\text { Lotes/Famí- } \\
\text { lia }\end{array}$ & Município \\
\hline $\begin{array}{c}\text { Assentamento } \\
\text { mais antigo }\end{array}$ & $\begin{array}{c}\text { Água } \\
\text { Sumida }\end{array}$ & 1988 & Incra & 121 & $\begin{array}{c}\text { Teodoro } \\
\text { Sampaio }\end{array}$ \\
\hline $\begin{array}{c}\text { Assentamento } \\
\text { mais antigo }\end{array}$ & $\begin{array}{c}\text { Gleba XV de } \\
\text { Novembro }\end{array}$ & 1984 & Itesp & 572 & $\begin{array}{c}\text { Euclides da } \\
\text { Cunha/Rosana }\end{array}$ \\
\hline $\begin{array}{c}\text { Assentamento } \\
\text { mais novo }\end{array}$ & $\begin{array}{c}\text { Dona } \\
\text { Carmem }\end{array}$ & 2008 & Incra & 185 & $\begin{array}{c}\text { Mirante do } \\
\text { Paranapanema }\end{array}$ \\
\hline $\begin{array}{c}\text { Assentamento } \\
\text { mais novo }\end{array}$ & Zilda Arns & 2011 & Itesp & 9 & $\begin{array}{c}\text { Teodoro } \\
\text { Sampaio }\end{array}$ \\
\hline
\end{tabular}


PERSPECTIVAS EM DIÁLOGO: Revista de Educação e Sociedade

\begin{tabular}{|c|c|c|c|c|c|}
\hline $\begin{array}{c}\text { Assentamento } \\
\text { maior }\end{array}$ & $\begin{array}{c}\text { Dona } \\
\text { Carmem }\end{array}$ & 2008 & Incra & $\begin{array}{c}\text { Mirante do } \\
\text { Paranapanema }\end{array}$ & $\begin{array}{c}\text { Euclides da } \\
\text { Cunha/Rosana }\end{array}$ \\
\hline $\begin{array}{c}\text { Assentamento } \\
\text { maior }\end{array}$ & $\begin{array}{c}\text { Gleba XV de } \\
\text { Novembro }\end{array}$ & 1984 & Itesp & 29 & Caiuá \\
\hline $\begin{array}{c}\text { Assentamento } \\
\text { menor }\end{array}$ & Engenho II & 1998 & Incra & 6 & $\begin{array}{c}\text { Presidente } \\
\text { Bernardes }\end{array}$ \\
\hline $\begin{array}{c}\text { Assentamento } \\
\text { menor }\end{array}$ & $\begin{array}{c}\text { Santa } \\
\text { Eudóxia }\end{array}$ & 1996 & Itesp & & 29 \\
\hline
\end{tabular}

Fonte: Compilação de Dados do Incra e do Itesp (2018).

Já nos Assentamentos menores (Engenho II, Santa Eudóxia e Zilda Arns) optamos por fazer censo, ou seja, pesquisar todos os lotes que continham idosos (as).

Depois da definição de nossa amostragem de idosos (as) cabe dizer que na pesquisa de campo nossos entrevistados foram escolhidos aleatoriamente, principalmente, respeitando a quantidade de idosos (as) em relação a paridade de gênero.

É salutar dizer também que antes de cumprirmos nossa amostragem de campo, levamos em consideração a vontade dos idosos (as) em participarem da pesquisa por livre e espontânea vontade, e isso nos foi resguardado através do TCLE (Termo de Consentimento Livre e Esclarecido - Comitê de Ética número de CAE: 97398818.0.0000.5404), que assegurava o sigilo dos participantes, além disso, outro critério adotado foi de que os respondentes estivessem em boas condições físicas e psicológicas para nos atender, para que não houvesse nenhum constrangimento, intimidação ou imposição a participação na pesquisa.

Ao todo foram entrevistados 177 idosos (as), com idades que variavam entre 60 e 91 anos.

\subsection{Instrumentos de Pesquisa}

O primeiro instrumento de pesquisa delineado foi o questionário semiestruturado. Este por sua vez, foi composto por 90 questões abertas e fechadas. Todavia, neste artigo, serão apresentados os resultados relativos a aposentadoria rural.

As justificativas para o uso do questionário foram para responder as questões de cunho socioeconômico e que trouxeram de modo significativo um retrato dos idosos e idosas dos Assentamentos Rurais do Pontal do Paranapanema.

A opção pelo questionário semiestruturado baseou-se em Gil (2007), é uma técnica de pesquisa das mais utilizadas consistindo em um instrumento de coleta de informações que apresenta muitas vantagens, pois possibilita de forma rápida o conhecimento de opiniões, crenças, sentimentos, interesses, expectativas, situações vivenciadas, entre outras.

Tecnicamente falando, o questionário constitui-se como um meio de obter respostas sobre determinado assunto de maneira que o respondente forneça as informações de seu domínio e conhecimento, por outro lado, todo questionário deve ser impessoal, para assegurar a uniformidade na avaliação de uma situação (CERVO; BERVIAN, 1996). 
Para afinarmos nossas análises acerca deste complexo universo do envelhecimento, optamos pela Análise de Segmentação/Conglomerados (Cluster) para conhecermos grupos homogêneos que apresentavam similaridades para que assim pudéssemos escolher os idosos (as) para esta segunda etapa, coletando dos mesmos relatos/depoimentos orais sobre o processo do envelhecer.

Através da Análise de Cluster pudemos dentre os 177 idosos (as) pesquisados na primeira fase, escolher mais 16 idosos (as), destes sendo (4) suplentes para coletarmos os depoimentos orais para compreendermos subjetivamente o processo de envelhecimento. Tínhamos a compreensão de que era necessário dar voz e vez a grupos e indivíduos historicamente marginalizados e invisibilizados, isso se justifica pelo fato de estarmos trabalhando com a categoria dos idosos e idosas e mais ainda, por estes atores estarem inseridos e serem protagonistas da luta pela terra e estarem hoje em Assentamentos de Reforma Agrária, o que dentro da diversidade da Agricultura Familiar brasileira, os torna uma categoria também com especificidades.

Logo, a importância de se dar voz e protagonismo a estes sujeitos nos remetem as palavras de Queiroz (1988 p.16) quando diz "a experiência indizível que se procura traduzir em vocábulos" [...] "passagem daquilo que está obscuro para uma primeira nitidez - a nitidez da palavra".

Esse rito de passagem do indizível a nitidez da palavra se traduziu quando utilizamos a história oral como norte. Sabe-se que o uso da fonte oral se dá como a maior forma de transmissão de conhecimento, saberes e de experiências nas sociedades humanas, e foi através das destas que a Ciência caminhou durante séculos, bem como também no decorrer da oralidade que foi e é possível reconstruir desde o passado longínquo aos relatos dos dias atuais (QUEIROZ, 1988).

Diante destes depoimentos, recortamos os trechos em que os idosos e idosas falavam, especificamente, da aposentadoria, desde a dificuldade ou facilidade do acesso ao benefício, como que este transformou ou não suas vidas no meio rural, principalmente, na questão da produção e trabalho, cada trecho está especificado com o nome do idoso ou idosa e em itálico.

\section{Resultados e Discussão}

No quesito aposentadoria, os (as) idosos (as) pesquisados foram questionados se possuíam ou não o benefício, e $89 \%$ dos (das) idosos (as) entrevistados disseram possuir o benefício, seguidos de $1 \%$ de pensionistas e de $10 \%$ que ainda não tinham conseguido acessar o benefício ou que este havia sido cortado pelo Governo Federal pela falta do comparecimento No exame de "prova de vida". Ao iniciar o trabalho de campo em 2018, estava em discussão a nova Reforma da Previdência do Governo Temer, bem como o "pente-fino" do governo em aposentadorias por invalidez e no recebimento de benefícios como o auxílio-doença.

Essa ação do Governo Federal em 2018 veio prejudicar muitos idosos (a) do meio rural. Em pesquisa de campo, encontrou-se três situações dessas, sendo uma delas um senhor cadeirante. 
Nos estudos de Beltrão, Camarano e Mello (2004), analisando a situação da população rural brasileira a respeito da Previdência Social, pode-se constatar que, apesar de o benefício previdenciário ter a função específica de servir como seguro contra perda de capacidade laboral, é inegável a importância da previdência rural na elevação da renda no campo e, consequentemente, na diminuição da pobreza.

Para Brumer (2002), o acesso à aposentadoria de homens e mulheres no meio rural provocou uma "revalorização e dignificação" da pessoa idosa, sobretudo do meio rural. Estes tornaram-se provedores e não mais dependentes de outras pessoas (filhos, netos, cuidadores e tutores).

Essa sensação de autonomia e bem-estar ficou evidente no aumento da renda e da qualidade de vida e, ao contrário, do que se assiste no meio urbano, o recebimento do benefício no meio rural não os afastou de suas atividades cotidianas, nem de seu meio social.

Correlacionar a questão de gênero e a aposentadoria rural se faz importante, pois historicamente a posição da mulher no meio rural foi correlacionada a uma posição subalterna, ou seja, de submissão e subordinação em relação ao homem e, por conseguinte, muitas vezes o recebimento da aposentadoria the confere autonomia e independência, dando-Ihes a oportunidade de experimentar coisas e situações que antes nunca puderam vivenciar, Tabela 1.

Tabela 1 - Distribuição da aposentadoria por gênero entre os (as) idosos (as) pesquisados - Pontal do Paranapanema (SP).

\begin{tabular}{|c|c|c|c|c|c|c|}
\hline Aposentadoria & \multicolumn{2}{|c|}{ Aposentado } & \multicolumn{2}{|c|}{$\begin{array}{c}\text { Não } \\
\text { Aposentado }\end{array}$} & \multicolumn{2}{|c|}{ Pensionista } \\
\hline Assentamentos & $\mathrm{H}$ & M & $\mathrm{H}$ & $M$ & $\mathrm{H}$ & M \\
\hline Gleba XV de Novembro & 26 & 31 & 2 & 0 & 0 & 2 \\
\hline Dona Carmem & 21 & 20 & 3 & 8 & 0 & 0 \\
\hline Água Sumida & 25 & 24 & 0 & 1 & 0 & 0 \\
\hline Engenho & 6 & 4 & 1 & 1 & 0 & 0 \\
\hline Zilda Arns & 0 & 0 & 1 & 0 & 0 & 0 \\
\hline Santa Eudóxia & 1 & 0 & 0 & 0 & 0 & 0 \\
\hline Subtotal & 79 & 79 & 7 & 10 & 0 & 2 \\
\hline Total $(\mathrm{H}+\mathrm{M})$ & & & & & & \\
\hline
\end{tabular}

Fonte: Dados da pesquisa (2019).

O recebimento de benefício da Previdência Social redefiniu o papel social dos idosos nas famílias e comunidades rurais brasileiras. A mudança nos papéis é particularmente evidente no caso das mulheres, que agora possuem uma fonte de renda própria. Mesmo quando as mulheres idosas continuam morando com seus filhos, a relação é qualitativamente diferente. Também é importante enfatizar que, em vez da erosão dos laços familiares, a solidariedade nas famílias normalmente é fortalecida com o sistema de aposentadorias e pensões não contributivas (SCHWARZER; QUERINO, 2002, p.19).

Para os (as) 158 idosos (as) aposentados (as) e 2 pensionistas, questionou-se sobre quem tinha os auxiliados a conseguirem o benefício da aposentadoria ou da pensão. Desses, 149 idosos (as) justificaram quem tinha 
os auxiliados, e as respostas foram diversas, como: "Consegui por conta própria/sozinho (a)", "Ajuda dos familiares", "Ajuda do sindicato", "Ajuda de advogado", "Ajuda de médico", entre outras respostas. Dessa maneira, apresentamos no Quadro 6 a seguir as respostas dos (das) idosos (as).

\section{Quadro 2 - Distribuição e correlação do auxiliador dos (das) idosos (as) pesquisados para conseguirem aposentadoria e a frequência das respostas dadas por eles - Pontal do Paranapanema (SP).}

\begin{tabular}{|c|c|}
\hline $\begin{array}{c}\text { De quem veio o auxílio para conseguir a } \\
\text { aposentadoria }\end{array}$ & $\begin{array}{c}\text { Frequência das respostas } \\
\text { dos idosos (as) }\end{array}$ \\
\hline pesquisados \\
\hline Conseguiu por conta própria & 70 \\
\hline Ajuda do Sindicato Rural & 51 \\
\hline Ajuda de familiares & 10 \\
\hline Ajuda de lideranças dentro do assentamento & 9 \\
\hline Ajuda de médicos & 5 \\
\hline Itesp & 4 \\
\hline
\end{tabular}

Fonte: Dados da pesquisa (2019).

Também se questionou aos (às) idosos (as) se a aposentadoria havia modificado suas vidas ou não. $79 \%$ afirmaram que houve mudanças significativas, outros $12 \%$ disseram que não houve mudanças significativas, e $9 \%$ dos entrevistados não quiseram responder.

Bem como indagou-se se a aposentadoria havia modificado a vida cotidiana deles. Neste caso, as respostas foram as mais diversas possíveis. Dessa forma, compilamos e agrupamos as respostas mais semelhantes e suas respectivas frequências em cada um dos assentamentos pesquisados, como se segue no Quadro 3.

Quadro 3 - Distribuição das justificativas com relação à mudança de vida trazida pelo benefício da aposentadoria e as respectivas frequências de respostas dadas pelos (pelas) idosos (as) pesquisados Pontal do Paranapanema (SP).

\begin{tabular}{|c|c|}
\hline \multicolumn{2}{|l|}{ Assentamento Gleba XV de Novembro } \\
\hline $\begin{array}{c}\text { Justificativas em relação à mudança de vida ou não depois do } \\
\text { benefício da aposentadoria }\end{array}$ & $\begin{array}{l}\text { Frequência das } \\
\text { respostas }\end{array}$ \\
\hline Melhorou as condições de vida/Melhorou & 13 \\
\hline Garantia de renda fixa/Garantia de poder pagar as contas mensais & 12 \\
\hline Ajudou muito, pois agora não precisava trabalhar tanto na roça & 10 \\
\hline Garantia para comprar os remédios mensais & 5 \\
\hline Compra de alimentos e compra de itens para casa e lote & 6 \\
\hline Benefício é muito pouco & 3 \\
\hline \multicolumn{2}{|l|}{ Assentamento Dona Carmem } \\
\hline $\begin{array}{c}\text { Justificativas em relação à mudança de vida ou não depois do } \\
\text { benefício da aposentadoria }\end{array}$ & $\begin{array}{l}\text { Frequência das } \\
\text { respostas }\end{array}$ \\
\hline Melhorou as condições de vida/Melhorou & 8 \\
\hline
\end{tabular}

Perspectivas em Diálogo, Naviraí, v. 8, n. 18, p. 293-213, jul/dez. 2021. 


\begin{tabular}{|c|c|}
\hline Garantia de renda fixa/Garantia de poder paga & 8 \\
\hline Ajudou muito, pois agora não precisava trabalhar tanto na roça & 12 \\
\hline Garantia para comprar os remédios mensais & 5 \\
\hline Compra de alimentos e compra de itens para casa e lote & 2 \\
\hline Benefício é muito pouco/Não ajudou muito & 7 \\
\hline \multicolumn{2}{|l|}{ Assentamento Água Sumida } \\
\hline $\begin{array}{c}\text { Justificativas em relação à mudança de vida ou não depois do } \\
\text { benefício da aposentadoria }\end{array}$ & $\begin{array}{l}\text { Frequência das } \\
\text { respostas }\end{array}$ \\
\hline Salário garantido/Renda fixa & 13 \\
\hline Ajuda nas despesas da casa/Ajuda a pagar as contas do mês & 10 \\
\hline $\begin{array}{c}\text { Melhorou, pois não precisa mais trabalhar tanto na roça/ Hoje } \\
\text { trabalho menos na roça }\end{array}$ & 6 \\
\hline Ajuda nas compras de remédios & 4 \\
\hline Melhorou de vida/Vida mais tranquila & 7 \\
\hline Sim, pois o lote dá pouco dinheiro e é a única renda que temos & 3 \\
\hline $\begin{array}{c}\text { Não ajudou/Benefício é pouco/Ficou a mesma coisa/Divide o } \\
\text { benefício com os filhos }\end{array}$ & 6 \\
\hline \multicolumn{2}{|l|}{ Assentamento Engenho } \\
\hline $\begin{array}{c}\text { Justificativas em relação à mudança de vida ou não depois do } \\
\text { benefício da aposentadoria }\end{array}$ & $\begin{array}{l}\text { Frequência das } \\
\text { respostas }\end{array}$ \\
\hline Melhorou as condições de vida/Melhorou & 4 \\
\hline Garantia de renda fixa/Garantia de poder pagar as contas mensais & 2 \\
\hline Ajudou muito, pois agora não precisava trabalhar tanto na roça & 1 \\
\hline Garantia para comprar os remédios mensais & 2 \\
\hline Compra de alimentos e compra de itens para casa & 1 \\
\hline \multicolumn{2}{|l|}{ Assentamento Santa Eudóxia } \\
\hline $\begin{array}{l}\text { Justificativas em relação à mudança de vida ou não depois do } \\
\text { benefício da aposentadoria }\end{array}$ & $\begin{array}{l}\text { Frequência das } \\
\text { respostas }\end{array}$ \\
\hline Ótimo, agora tenho garantia & 1 \\
\hline
\end{tabular}

Fonte: Dados da pesquisa (2019).

Com relação ao benefício da aposentadoria, também foi questionado como os (as) idosos (as) se sentiam por receber o benefício. Nessa questão os (as) idosos (as) foram enfáticos com relação aos sentimentos que eram atribuídos ao benefício, como explicitado para todos os assentamentos pesquisados no Quadro 4. Vale dizer que também compilamos e agrupamos as respostas mais semelhantes e suas respectivas frequências em cada um dos assentamentos.

Quadro 4 - Distribuição das justificativas com relação aos sentimentos que eram atribuídos ao benefício da aposentadoria e respectivas frequências de respostas dos (das) idosos (as) pesquisados - Pontal do Paranapanema (SP).

\begin{tabular}{|c|c|}
\hline \multicolumn{2}{|c|}{ Assentamento Gleba XV de Novembro } \\
\hline $\begin{array}{c}\text { Justificativas com relação aos sentimentos } \\
\text { atribuídos ao benefício da aposentadoria }\end{array}$ & $\begin{array}{c}\text { Frequência das } \\
\text { respostas }\end{array}$ \\
\hline \multicolumn{2}{|c|}{ Aem/Felicidade/Satisfação } \\
\hline \multicolumn{2}{|c|}{ Assentamento Dona Carmem } \\
\hline $\begin{array}{c}\text { Justificativas com relação aos sentimentos } \\
\text { atribuídos ao benefício da aposentadoria }\end{array}$ & $\begin{array}{c}\text { Frequência das } \\
\text { respostas }\end{array}$ \\
\hline
\end{tabular}




\begin{tabular}{|c|c|}
\hline Bem/Felicidade/Satisfação/Garantia/Tranquilidade/Sossego & 19 \\
\hline Pior/ Mesma coisa/Não ajudou muito & 4 \\
\hline Medo da Reforma da Previdência & 3 \\
\hline \multicolumn{2}{|l|}{ Assentamento Água Sumida } \\
\hline $\begin{array}{l}\text { Justificativas com relação aos sentimentos } \\
\text { atribuídos ao benefício da aposentadoria }\end{array}$ & $\begin{array}{l}\text { Frequência das } \\
\text { respostas }\end{array}$ \\
\hline $\begin{array}{l}\text { Bem/Felicidade/Satisfação/Segurança/Benção/ } \\
\text { Tranquilidade }\end{array}$ & 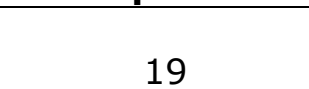 \\
\hline Melhorou, mas estou com empréstimos & 3 \\
\hline \multicolumn{2}{|l|}{ Assentamento Engenho } \\
\hline $\begin{array}{l}\text { Justificativas com relação aos sentimentos } \\
\text { atribuídos ao benefício da aposentadoria }\end{array}$ & $\begin{array}{c}\text { Frequência das } \\
\text { respostas }\end{array}$ \\
\hline Bem/Felicidade/Satisfação & 8 \\
\hline \multicolumn{2}{|l|}{ Assentamento Santa Eudóxia } \\
\hline $\begin{array}{l}\text { Justificativas com relação aos sentimentos } \\
\text { atribuídos ao benefício da aposentadoria }\end{array}$ & $\begin{array}{c}\text { Frequência das } \\
\text { respostas }\end{array}$ \\
\hline Ótimo, agora tenho garantia & 1 \\
\hline
\end{tabular}

Fonte: Dados da pesquisa (2019).

Quando perguntados se após a aposentadoria continuavam responsáveis pela produção no lote, $59 \%$ afirmaram que sim, seguidos por $34 \%$ que afirmaram que não. Se fizermos uma correlação com a questão da titularidade do lote, estas se sobrepõem, levando-nos a deduzir que, se o idoso ou a idosa é titular do lote, este também ainda é o (a) responsável pela unidade de produção, organização da produção, tendo também um poder decisório. Para além desses valores, o que observamos durante a pesquisa foram idosos (as) muito ativos nos lotes, mesmo com o avançar da idade.

Aos que responderam negativamente, indagamos quem era, atualmente, os (as) responsáveis pelo lote, e as respostas são representadas na Figura 23. Nessa questão, dos 59 idosos (as) que afirmaram não serem responsáveis, apenas 34 justificaram quem era o novo responsável pelo lote. Nota-se que, se somarmos o número de sujeitos do sexo masculino, encontraremos 20 homens, em detrimento de 14 mulheres, que atualmente são responsáveis pelo lote e pela produção. A hipótese que se alicerça é a de que a questão sucessória no meio rural tem forte apelo masculino. 


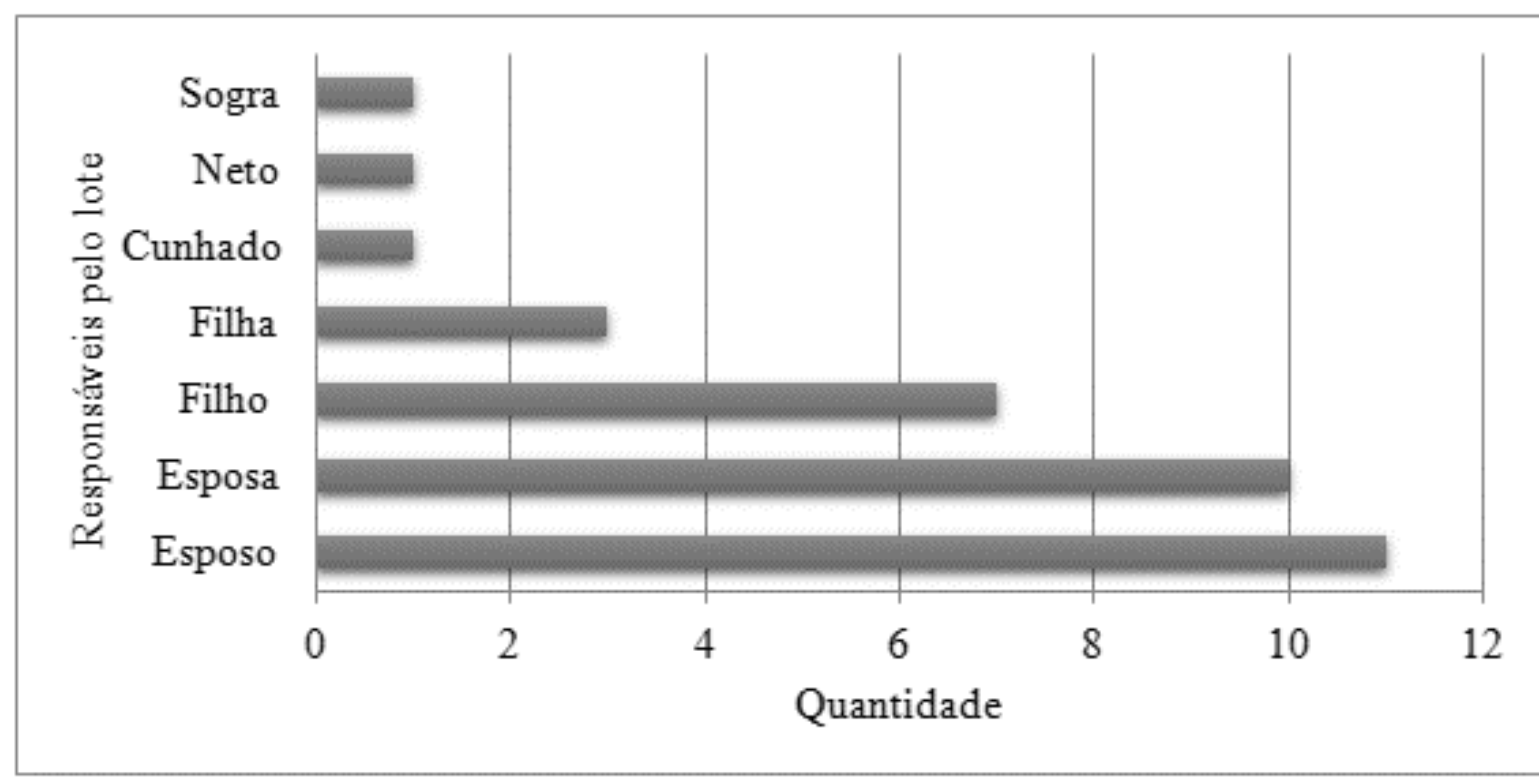

Figura 1: Distribuição com relação à responsabilidade do lote atualmente, segundo os (as) idosos (as) pesquisados - Pontal do Paranapanema (SP).

Dados da pesquisa (2019).

Perguntou-se aos (às) idosos (as) se após aposentadoria eles tinham feito alguma melhoria/benfeitoria no lote, na casa, ou se adquiriram algum bem material. Dos 158 idosos (as) que são beneficiados pela aposentadoria, 102 (58\%) fizeram algum tipo de melhoria/benfeitoria, seja no lote, seja na casa, ou compraram bens materiais; outros $33 \%$ afirmaram que não fizeram nenhuma mudança, e $9 \%$ não responderam.

Desses 102 idosos (as), quisemos saber quais tinham sido essas mudanças/melhorias e aquisição de bens materiais após aposentadoria. Como resultado, obtivemos respostas diversas, como apresentadas no Quadro 9, a seguir. Dessa forma, compilamos e agrupamos as respostas mais semelhantes e suas respectivas frequências em cada um dos assentamentos.

\section{Quadro 9 - Distribuição dos tipos de mudanças/benfeitorias realizadas nos lotes dos (das) idosos (as) pesquisados após a aposentadoria - Pontal do Paranapanema (SP).}

\begin{tabular}{|c|c|}
\hline \multicolumn{2}{|c|}{ Assentamento Gleba XV de Novembro } \\
\hline $\begin{array}{c}\text { Mudanças realizadas nos lotes após } \\
\text { aposentadoria }\end{array}$ & $\begin{array}{c}\text { Frequência das } \\
\text { respostas }\end{array}$ \\
\hline Construção da casa/Reforma da casa & 26 \\
\hline $\begin{array}{c}\text { Compra de móveis e eletrodomésticos } \\
\text { barracão, compra de animais (aves e gado)) }\end{array}$ & 17 \\
\hline Compra de carro e caminhão & 3 \\
\hline Assentamento Dona Carmem & $\begin{array}{c}\text { Frequência das } \\
\text { respostas }\end{array}$ \\
\hline $\begin{array}{c}\text { Mudanças realizadas nos lotes após } \\
\text { aposentadoria }\end{array}$ & 12 \\
\hline Construção da casa/Reforma da casa & 4 \\
\hline Compra de móveis e eletrodomésticos & \\
\hline
\end{tabular}


Melhorias no lote (pasto, mangueirão, poço artesiano, barracão, compra de animais (aves e gado))

3

\begin{tabular}{|c|c|}
\hline \multicolumn{2}{|l|}{ Assentamento Água Sumida } \\
\hline $\begin{array}{c}\text { Mudanças realizadas nos lotes após } \\
\text { aposentadoria }\end{array}$ & $\begin{array}{l}\text { Frequência das } \\
\text { respostas }\end{array}$ \\
\hline Construção da casa/Reforma da casa & 15 \\
\hline Compra de móveis e eletrodomésticos & 13 \\
\hline Melhorias no lote (pasto, mangueirão, poço artesiano) & 3 \\
\hline Compra de carro e caminhão & 1 \\
\hline \multicolumn{2}{|l|}{ Assentamento Engenho } \\
\hline $\begin{array}{c}\text { Mudanças realizadas nos lotes após } \\
\text { aposentadoria }\end{array}$ & $\begin{array}{l}\text { Frequência das } \\
\text { respostas }\end{array}$ \\
\hline Construção da casa/Reforma da casa & 3 \\
\hline Compra de móveis e eletrodomésticos & 2 \\
\hline $\begin{array}{c}\text { Melhorias no lote (pasto, mangueirão, poço artesiano, } \\
\text { barracão, compra de animais (aves e gado)) }\end{array}$ & 2 \\
\hline Compra de carro e caminhão & 1 \\
\hline
\end{tabular}

Fonte: Dados da pesquisa (2019).

Analisando os trechos dos depoimentos que retratam a questão da aposentadoria dos idosos e das idosas, encontramos diversas possibilidades de interpretação para cada indivíduo. Para os que conseguiram o benefício, a sensação é de uma maior tranquilidade, pois conseguem garantir o mínimo, desde medicamentos, alimentação etc. Aos que ainda não conseguiram, fica evidente a apreensão e os percalços inerentes a este processo.

Graças a Deus, quando eu fui me aposentar, já estava com quase 64 anos já, porque eu não tinha documento nenhum. É, não tinha carteira registrada nem nada, porque eu nunca trabalhei e tive que ter o comprovante, como eu era junta com ela. Foram quatro anos para me aposentar. Não tinha carteira registrada, minha carteira era em branco. Tinha a carteira, mas era em branco, porque nunca fui... nunca trabalhei registrada, né, era manual. Foi. Foram três advogados. Uns quatro anos para poder me aposentar. É e eu dou graças a Deus (Dona Ana, assentamento Gleba XV de Novembro).

Na fala de dona Ana, é perceptível essa dificuldade que idosos (as) do meio rural têm muitas vezes para comprovar o trabalho no campo para conseguirem 0 benefício, precisando gastar com advogados para tal comprovação e tempo de serviço.

Seu Antônio relata as dificuldades de viver no lote, e que se não fosse o benefício, ele e sua família já tinham saído do assentamento. Também declara que, com o dinheiro da aposentadoria, conseguiu comprar um carro, mas que este estava "batido" e que, por conta de empréstimos feitos com a aposentadoria, não conseguia arrumar o carro.

Durante a pesquisa de campo, uma das principais queixas nos assentamentos era a questão de transporte, principalmente no assentamento Gleba XV de Novembro, pois este se encontra bem distante da cidade, e o transporte público havia sido suspenso pelas prefeituras de Rosana e Euclides 
da Cunha Paulista, só permanecendo o transporte escolar e da saúde, mas estes as pessoas não podiam utilizar, ficando à mercê de carona, de transporte clandestino ou de favores de vizinhos e parentes para compras na cidade, para uma emergência ou para qualquer outra demanda.

Ficou claro durante o período da pesquisa o medo de muitos idosos (as) de sermos agentes de financeiras de créditos para aposentados, pois alguns relataram ter sofrido golpes do empréstimo na aposentadoria. Muitos assentados tinham empréstimos na aposentadoria.

A mulher está aposentada, eu estou aposentado. Se não fosse a aposentadoria, minha filha, acho que nós já tínhamos vendido e ido embora. Só vive à base de medicamento. É, a maior parte é do posto. Muitos tem que comprar. Não são todos, mas uns precisa comprar. Isso nos toma a aposentadoria. Já porque esse carro aí que está batido, nós o compramos novinho aqui, com o dinheiro de aposentadoria nosso, mas agora não compra mais, porque agora tem esse tal de empréstimo, empréstimo deixa o salário desse tamanhozinho, igual o Chico Anysio, pequeninho (Seu Antônio, Assentamento Gleba XV de Novembro).

Em outro trecho, seu Antônio relata que a maior renda do lote vem da aposentadoria, e às vezes consegue fazer alguma venda no lote. Acrescentou que o dinheiro da aposentadoria também é investido no lote. "É da aposentadoria. De vez em quando, quando vende algum bezerro, pega um dinheirinho extra, mas tem que gastar no lote, você tem que gastar no próprio gado, então..." (Seu Antônio, assentamento Gleba XV de Novembro).

O papel da aposentadoria na renda dos (das) idosos (as) é mais do que simplesmente contribuir para o orçamento familiar, ela também é utilizada para custear a produção agrícola e manter a infraestrutura da unidade produtiva. Vale dizer ainda que aposentadoria é por muitas vezes a única renda existente por muitos meses do ano, principalmente porque a agricultura é uma atividade de risco, no que se diz respeito a fatores climáticos (BELTRÃO; OLIVEIRA; PINHEIRO, 2000).

Com relação à dificuldade de se conseguir o benefício, à conjuntura política e econômica e à então nova Reforma da Previdência (PEC no 287) que estava em discussão na época da pesquisa, alguns assentados que não eram aposentados estavam apreensivos com o que poderia acontecer. Passada a reforma e sua promulgação, não houve mudanças com relação aos trabalhadores rurais, no entanto, muitos relataram não confiar na atual conjuntura política e econômica, e isso poderia de alguma forma afetá-los.

Ah, eu nem sei se... Eu acho que não, porque quando eles aprovaram a reforma eu já estava na idade de aposentar, eu não vou entrar nessa regra nova, continuo na velha, mas não sei, o advogado falou que é tranquilo, falou: "Tem que entrar, o sistema é lento". Então, porque no sistema antigo eu não tenho essas notas para poder provar isso aí, mas na regra passada tanto você prova com nota ou com testemunho de pessoas (Seu Claudemir, assentamento Dona Carmem).

Não, a minha aposentadoria ainda não saiu. Desde dezembro teve a audiência e o juiz deu parecer favorável, mas aí o INSS recorreu, aí foi 
para São Paulo, esperando a boa vontade do desembargador. Pelo amor de Deus, o Bolsonaro tem compaixão, não corta a aposentadoria das pessoas desse jeito, né? Porque pessoas que nem eu, eu ainda me sinto disposta a trabalhar, agora tem muitos coitados aí que... que ele colocasse a mão na consciência aí e fizesse as coisas certas, não fizesse as coisas erradas igual ele está fazendo aí não" (Dona Cida, assentamento Dona Carmem).

Nas palavras de Seu José e de sua esposa, dona Lourdes, a terra é para eles satisfação e segurança, e o benefício da aposentadoria veio para deixá-los ainda mais tranquilos na manutenção da vida, garantindo desde medicamentos mensais até as compras do mês, e ainda conseguem guardar um provento para qualquer eventualidade. Nas suas falas, é perceptível também que eles, inicialmente, tinham a ideia de que iriam ficar tranquilos após a aposentadoria, que não iriam mais "tirar leite", mas como trabalharam a vida toda, ficar sem fazer nada não é do feitio deles.

Para nós aqui, a terra é um lugar seguro, porque você sabe que se a gente estivesse pagando aluguel, enquanto a aposentadoria sai, não ia ter dinheiro. E a terra não, a terra é só cuidar dela que é um lugar seguro, e outra, dá para tirar muito da terra para alimento. Não para ganhar dinheiro, porque a gente já é pobre, não produz muita coisa, mas para sustentar a casa dá para tirar muito. Mudou sim, porque a gente muda, está mais sossegado, né, mas financeiramente, não está ruim, porque a gente tem, nós dois somos aposentados, então todo mês dá para você fazer sua comprinha e sempre tem o troquinho que você precisa numa emergência né, a gente segura o troco, né? Então, levando controlado, dá para viver. E aposentou também, já tem o medicamento, todo mês já dá para comprar alguma coisa, né, mas dá para viver, sim (Dona Lourdes, assentamento Gleba XV de Novembro).

Quando nós aposentamos, falei: "Não vamos mais tirar leite. Nós bebíamos muito leite. Aí aposentamos: "Vamos vender essas vacas velhas e vamos parar de tirar leite". Mas depois a gente sente falta, aí começamos a comprar só para tirar para beber, fazer um queijinho, tirar soro para o porco e comer o capim também, né? Parar é pior, se ficar só dentro de casa sentado, o dia que quiser levantar, não levanta (Seu José, assentamento Gleba XV de Novembro).

Diante disso, estudos que abordaram a velhice, a saúde e o trabalho no meio rural apontam que: "a carência de seguridade social obriga a trabalhar até idades muito avançadas e também por tradição, pois mulheres $e$, principalmente, os homens devem permanecer trabalhando, porque deixar de trabalhar é sinônimo de inatividade e anúncio de decadência (MORAIS; RODRIGUES; GERHARDT, 2008, p.380).

Dados da Síntese de Indicadores Sociais: uma análise das condições de vida da população brasileira afirmam que:

Em relação ao rendimento familiar per capita, 75,6\% dos idosos de 60 anos ou mais de idade eram aposentados e/ou pensionistas, em 2015, e que $69,0 \%$ do rendimento das pessoas nesta mesma faixa etária era proveniente de aposentadoria ou pensão, pode-se dizer que a menor vulnerabilidade monetária dos idosos, e dos familiares que residem com 
eles, estaria associada ao recebimento destes benefícios (IBGE, 2016, p.32).

Em termos simbólicos, a aposentadoria confere aos (às) idosos (as) a sensação de tranquilidade e segurança, todavia não os afasta das atividades cotidianas, principalmente do trabalho na propriedade rural; ao passo que muitas vezes a aposentadoria no meio urbano retira dos (das) idosos (as) o espaço de sociabilidade proporcionada pelo trabalho, deixando um sentimento de vazio e de inutilidade (BRUMER, 2002).

Graças a Deus. Minha aposentadoria não deu trabalho nenhum, consegui me aposentar, hoje eu sou aposentada... É difícil. Eu consegui, eu falava em reunião, o dia que eu completar 55 anos, no dia 16, dia 17, eu estaria no INSS para me aposentar. Na época o prefeito era mulher, ela tirava um sarro. Eu falava para as mulheres todas, ninguém acreditava, mas eu não estava mentindo, eu estava falando a verdade: "Gente, eu vou fazer 55 no final da semana, no dia 17 eu estou no INSS". Aí ninguém acreditava e eu já tinha cada ano, cada ano eu colocava uma folha, tinha uma pasta, cada ano eu colocava uma folha, aí só faltava a folha daquele mês. Aí quando foi dia 21, eu voltei lá. Aí já saí de lá aposentada. Com 13 dias eu fui e recebi, mas eu acho, assim, envelhecer no assentamento, eu acho que é uma boa. Eu não me vejo, assim. Se não tivesse a aposentadoria, você acha... Eu não sei, eu confio, assim... Eu falo com seu Paulo: "Tem que comprar tal remédio". Tira foto da receita e manda, em meia hora o remédio está aqui. Mas se fosse para um filho me segurar, assim, com alimento, cesta básica... Você acha que mês e mês ia conseguir? Eu acho que os velhos, antigamente, sofriam muito e era muito abandono de velho porque não tinha aposentadoria (Dona Nice, assentamento Gleba XV de Novembro).

Maior alegria? Ah, sei lá. Ah, quando eu aposentei. Isso, é. Não, tudo era alegria direto, mas quando veio a aposentadoria, aí ficou mais legal ainda. (Luiz Joaquim, assentamento Gleba XV de Novembro)

Se eu não tivesse pegado essa terra, acho que nós dois, até hoje, nós não éramos aposentados, porque a gente quando fez 15 anos de contribuição, como falam, eles aposentaram a gente, com 15 anos. Nós moramos lá mais de 15 anos, nós moramos lá uns 15 anos lá no Roseli, porque a minha neta vai fazer 19 , ela não era nascida quando pegamos lá. É isso mesmo. Porque a gente aposenta, quem é sem-terra aposenta rápido por causa do tempo de serviço, mas quem não é, com essa lei agora, agora que ninguém vai aposentar mesmo (Dona Maria, assentamento Dona Carmem).

Só não criei os 11 filhos porque um faleceu. Esse lote aqui... Nós pegamos aí eu nunca vendi, não vendia, nunca pensei em vender e agora não vou vender porque passei para o meu filho. Porque chegou uma época que eu não estou conseguindo trabalhar mais, tirar leite, e ficar um cara como eu, na idade que eu estou, aposentado, cultivando o lote só porque é meu? Meu filho está desempregado, não tem terra para trabalhar, "o lote é seu", então trabalha e tudo se ajeita. Aí graças a Deus, passei o lote para ele, o lote é dele. (Seu João Xavier, assentamento Gleba XV de Novembro). 
As reflexões que se colocam diante destas falas é de que retratam o contexto socioeconômico em que vivemos nos últimos tempos, retrato de políticas de cunho neoliberal por parte do Estado brasileiro e, por outro lado, o encolhimento de políticas sociais de cunho redistributivo de renda e que atendam os anseios dos mais pobres.

Da mesma forma que retrata um país que deixou a Reforma Agrária e as políticas socioeconômicas do rural em segundo plano, deixando assim, quem vive ali e que presta um serviço imprecificável como a produção de alimentos e serviços ambientais, quase a própria sorte.

Ainda nesta mesma reflexão, coloca-se o fato que não é apenas desapropriar terras e distribuí-las, a luta pela terra se desencadeia numa luta pela cidadania, pela melhoria da renda e melhores condições de vida, donde a previdência, mesmo que tardia aos rurais, talvez seja a única política pública mais ampla, contínua e mais capilarizada que tenha chegado no rural brasileiro até hoje.

Deste modo, também temos de levar em conta que a Previdência Social Rural chega apenas na transição da vida adulta para a velhice, ou seja, numa época da vida em que mesmos que os idosos e idosas na maioria das vezes não cessem o trabalho, a força laboral já não é a mesma, também se coloca que para os mais jovens quase não há oportunidades, nem condições para que a sucessão aconteça.

As falas denotaram também que grandes reformas ou minirreformas da previdência deixam em alertam, criam tensões significativas aos agricultores familiares.

\section{Considerações Finais}

Os resultados do presente trabalho ilustraram que sim, a Previdência no Meio Rural, está diretamente ligada a qualidade de vida e dignificação da pessoa idosa do meio rural. Seja pela melhoria no padrão de consumo, seja para melhoria das benfeitorias no lote, seja por deixar o idoso e a idosa em posição de protagonismo do cenário familiar, mantendo estes como provedores das famílias.

Quanto à aposentadoria no meio rural, esta vem a ser a "menina dos olhos", a menina dos olhos da permanência no meio rural, a menina dos olhos pela segurança, pela tranquilidade e todos os outros atributos trazidos pelos (las) idosos (as) nesta pesquisa.

A forte cobertura previdenciária dos (das) idosos (as) entrevistados (as) permite que estes escolham permanecer no campo, mesmo com todos os dilemas, produzindo para subsistência ou não, mas mantendo seu modo de vida e sua identidade. Embora houvesse uma preocupação com a nova Reforma da Previdência, esta não atingiu o campo, pois as idades mínimas para quem vai se aposentar continuam as mesmas.

A aposentadoria no meio rural está diretamente ligada à qualidade de vida e à dignificação da pessoa idosa, sobretudo da mulher idosa rural, seja pela melhoria no padrão de consumo, seja para melhoria das benfeitorias no lote, 
seja por deixar o idoso e a idosa em posição de protagonismo no cenário familiar, mantendo estes como provedores das famílias.

Nota-se a quantidade de idosos e idosas que utilizaram os benefícios a fim de reformar ou construir a casa própria. Portanto, vale destaque o simbolismo da moradia, que traz consigo sinais de dignificação da vida. Isso se destaca pelo fato de a maioria dos pesquisados trazer consigo a trajetória de luta pela terra, a passagem por acampamentos rurais à beira da estrada, dentre outras situações extremas, nas quais a casa e a morada fazem-se o lar, e que isso não tem preço!

Corroboram com esses resultados os sentimentos atrelados à aposentadoria, como: segurança, tranquilidade, felicidade e garantia de renda fixa, ilustrando mais ainda que a aposentadoria no meio rural, além de um aparato jurídico, excepcionalmente importante para estas pessoas, traduz, sobretudo, dignidade humana e reconhecimento por parte do Estado brasileiro.

\section{REFERÊNCIAS}

BARRETO, Maria Joseli.; THOMAZ JÚNIOR, Antônio. O cenário do agronegócio canavieiro na região do Pontal do Paranapanema-SP. In: XXI ENCONTRO NACIONAL DE GEOGRAFIA AGRÁRIA. Uberlândia: UFU, 2012.

BARROS, Vanessa Aparecida Moreira de. A aposentadoria rural e as mudanças nos modos de vida dos idosos que vivem no campo: em análise os municípios de Piranga e São Miguel do Anta, Minas Gerais. Dissertação (Mestrado em Ciências) - Universidade Federal de Viçosa, Viçosa, 2014. Disponível em: http://locus.ufv.br/bitstream/ha ndle/123456789/4209/texto\%20completo.pdf?sequence=1\&isAllowed=y. Acesso em: 27 jan. 2019.

BELTRÃO, Kaizô Iwakami.; OLIVEIRA, Francisco Eduardo Barreto de.; PINHEIRO, Sonoê Sugahara.; A população rural e a previdência social no Brasil: uma análise com ênfase nas mudanças constitucionais. Rio de Janeiro: IPEA, 2002.

BERWANGER, Jane Lucia Wilhelm. Previdência rural: inclusão social. $2^{a}$. Ed. Curitiba: Juruá, 2009.

BRUMER, Anita. Previdência social rural e gênero. Sociologias, Porto Alegre, ano 4. n. 7, jan/jun 2002, p. 50-81.

CERVO, Amado Luiz; BERVIAN, Pedro Alcino. Metodologia científica. São Paulo: Makron Books, 1996. 308p.

DELGADO, Guilherme da Costa. Previdência social e desenvolvimento rural. In: GRISA, Cátia; SCHNEIDER, Sergio. Políticas públicas de desenvolvimento rural no Brasil. Porto Alegre: Editora da UFRGS, 2015. 
DEZOTTI, Débora Fernandes; MARTA, Taís Nader. Marcos históricos da seguridade social. RVMD, Brasília, v. 5, n. 2, p. 430-459, 2011.

FERNANDES, Bernardo Mançano. MST: formação e territorialização. São Paulo: Hucitec, 1996.

FERRANTE, Vera Lucia Silveira Botta. Assentamentos Rurais no Território da Cana: controvérsias em cena. Revista NERA, Presidente Prudente, UNESP, v. 11 , p. 1-11, 2007.

GIL, Antônio Carlos. Métodos e técnicas de pesquisa social. $5^{a}$. Ed. São Paulo: Atlas, 2007.

IBGE: "A Síntese dos Indicadores Sociais 2016 - Uma Análise das Condições de Vida da População Brasileira". Disponível em: http://www.ibge.gov.br. Acesso em: 28 mar. 2018.

JARDIM, Rodrigo Guimarães. Antecedentes históricos da seguridade social no mundo e no Brasil. 2013. Disponível em:

http://jus.com.br/artigos/26145/antecedentes-historicos-da-seguridade-socialnomundo-e-no-brasil\#ixzz3dADCoFi0. Acesso em:15 jun. 2015.

MORAIS, Eliane Pinheiro de; RODRIGUES, Rosalina Aparecida Partezani.; GERHARDT, Tatiana Engel. Os idosos mais velhos no meio rural: realidade de vida e saúde de uma população do interior gaúcho. Texto Contexto, Florianópolis, v.17, n.2, p.374-383, 2008.

MARANHÃO, Rebecca Lima Albuquerque; VIEIRA FILHO, José Eustáquio Ribeiro., Previdenciária Rural no Brasil, Instituto de Pesquisa Econômica Aplicada - IPEA, 2018. Disponível em:

http://repositorio.ipea.gov.br/bitstream/11058/8690/1/td_2404.pdf. Acesso em: 20 jul. 2020.

PAIVA, Sálvea de Oliveira Campelo e. Envelhecimento, saúde e trabalho no tempo do capital. São Paulo: Cortez, 2014.

QUEIROZ, Maria Isaura Pereira de. Relatos orais: do "indizível" ao "dizível". Experimentos com histórias de vida: Itália-Brasil, [S.I.], [s.n.], 1988.

SCHWARZER, Helmut.; QUERINO, Ana Carolina. Benefícios sociais e pobreza: programas não contributivos da seguridade social brasileira. Brasília: IPEA, 2002.

TOMPKIN, John. Ries. Estatística e métodos de pesquisa em ciências sociais rurais. Piracicaba: Escola Superior de Agricultura Luiz de Queiroz, 1967. 
Recebido em: 8 de setembro de 2021.

Aceito em: 18 de outubro de 2021.

Publicado em: 15 de dezembro de 2021. 